\title{
Efeito da solarização e biofumigação na incidência da murcha bacteria- na em tomateiro no campo
}

\author{
Mírian J Baptista; Ronessa B de Souza; Welington Pereira; Carlos Alberto Lopes; Osmar A Carrijo \\ Embrapa Hortaliças, C. Postal 218, 70359-970 Brasília-DF; E-mail: mirian@cnph.embrapa.br
}

\section{RESUMO}

As doenças causadas por fitopatógenos do solo causam elevados prejuízos na maioria das espécies olerícolas. A solarização e a biofumigação são estratégias para controle destes organismos com potencial para aplicação em sistemas de manejo integrado. Neste trabalho, foi conduzido um experimento na Embrapa Hortaliças, Brasília - DF, para avaliar os efeitos da adição de resíduos orgâni$\cos$ (biofumigação) e da solarização na incidência natural da murcha-bacteriana do tomateiro, causada por Ralstonia solanacearum, nas características químicas do solo e na ocorrência de plantas invasoras. Os tratamentos avaliados foram adição de resíduos de brássicas $(2 \% \mathrm{v} / \mathrm{v})$, cama de frango $(2 \% \mathrm{v} / \mathrm{v})$, tratamento com brometo de metila e solo sem tratamento, todos solarizados ou não solarizados. Após a solarização, foram coletadas amostras de solo para determinação de suas características químicas e do banco de sementes de plantas invasoras. A solarização do solo provocou redução significativa no $\mathrm{pH}$ e nos teores de $\mathrm{B}$ e Zn. A adição de matéria orgânica ocasionou aumentos nos teores de $\mathrm{Ca}, \mathrm{K}$, e Na e reduziu os teores de Al. O banco de sementes de plantas invasoras, principalmente monocotiledôneas foi também reduzido significativamente. $\mathrm{O}$ tratamento com brometo de metila e a adição de cama de frango reduziram significativamente a incidência de murcha-bacteriana.

Palavras-chave: Lycopersicon esculentum, Ralstonia solanacearum, desinfestação do solo, controle físico.

\begin{abstract}
Effect of soil solarization and biofumigation on tomato bacterial wilt incidence.

Soilborne plant pathogens cause heavy losses to many vegetable crops. Solarization and organic residues amendments have been evaluated as disease control strategies with good perspectives for aplication in integrated management. Field experiments were carried out at Embrapa Hortaliças, Brasília-DF, to evaluate the effects of amending soil with organic residues (biofumigation) and solarization on the incidence of bacterial wilt (Ralstonia solanacearum) on tomato, on soil chemical characteristics, and weed control. Amendments with brassica residues (2\%), chicken litter residues (2\%), methyl bromide treatments and no soil treatment, with or without soil solarization were evaluated. After solarization and biofumigation, soil samples were collected for chemical analysis and weed seed bank evaluation. The tomato seedlings were transplanted after two months of soil solarization. Soil solarization reduced soil $\mathrm{pH}$ and levels of $\mathrm{B}$ and $\mathrm{Zn}$. Organic amendments increased levels of $\mathrm{Ca}, \mathrm{K}$ and $\mathrm{Na}$ and reduced levels of Al. Soil solarization reduced the number of weed seeds in the soil, mainly monocotyledons. Methyl bromide treatments and chicken litter amendments significantly reduced bacterial wilt incidence and disease progress.
\end{abstract}

Keywords: Lycopersicon esculentum, Ralstonia solanacearum, soil disinfestation, physical control.

\section{(Recebido para publicação em 11 de março de 2005; aceito em 31 de maio de 2006)}

\begin{abstract}
$\mathrm{A}$ s doenças causadas por organismos presentes no solo causam sérios problemas no cultivo de hortaliças e podem levar a perdas elevadas, em alguns casos chegando a $100 \%$ da produção. Em pequenas propriedades, cuja área disponível para produção é restrita, o problema causado pela presença de patógenos de solo pode levar à necessidade de abandono da área inviabilizando a propriedade para produção de determinadas culturas. A murcha bacteriana do tomateiro, causada por Ralstonia solanacearum está associada a solos encharcados e altas temperaturas, sendo mais problemática, e até limitante, no verão e em regiões de clima quente (Lopes et al., 2000). R. solanacearum infecta espécies de plantas pertencentes a mais de 50 famílias botânicas (Hayward, 1994), provocando maiores perdas nas solanáceas. Infecta ainda
\end{abstract}

várias plantas invasoras que mantêm altas populações da bactéria no solo, característica que dificulta o controle da doença no campo.

A solarização do solo vem sendo estudada como opção para o controle de doenças causadas por fitopatógenos do solo. Trata-se de um método de desinfestação realizado através da cobertura do solo úmido com filme de polietileno transparente, nas estações mais quentes do ano, antes do plantio (Katan, 1981). Esta técnica tem demonstrado ser efetiva no controle de patógenos de solo e no controle de plantas invasoras, tendo a vantagem de ser uma técnica simples, de baixo custo, e de não envolver o uso de produtos químicos, sendo assim ambientalmente valorizada (Ghini, 2001).

A biofumigação consiste na incorporação de matéria orgânica ao solo, principalmente resíduos de brássicas e resíduos ricos em nitrogênio, que durante a decomposição produzem substâncias tóxicas aos fitopatógenos reduzindo sua viabilidade no solo. A utilização da biofumigação juntamente com a solarização tem sido avaliada como alternativa para o controle de fitopatógenos do solo com bons resultados (Gamliel \& Stapleton, 1993a, 1993b; Blok et al., 2000). Estas técnicas podem permitir o controle mais eficiente da murcha bacteriana e a possibilidade de reduzir a população de $R$. solanacearum no solo, principalmente em estratégias de manejo integrado, aumentando as perspectivas de controle da doença. Este trabalho teve o objetivo de avaliar o efeito da solarização e da biofumigação, com adição de resíduos de brássicas e cama de frango, na incidência de murcha bacteriana em tomate, na 
sobrevivência de plantas invasoras e nas características químicas do solo.

\section{MATERIAL E MÉTODOS}

O experimento foi conduzido em área $(50 \times 25 \mathrm{~m})$ naturalmente infestada com Ralstonia solanacearum raça 1 , biovar 1, localizada no campo experimental da Embrapa Hortaliças, BrasíliaDF, 15'56'00" latitude sul, 4808'00'" longitude oeste, altitude 997,6 m. O solo, de textura argilosa (argila: 74,4\%; silte: $18,9 \%$; areia total: $6,7 \%$ ), foi preparado com aração até $30 \mathrm{~cm}$ de profundidade, uso de subsolador e de enxada rotativa. Foi feita irrigação até a capacidade de campo e no dia seguinte as parcelas a serem solarizadas foram cobertas com plástico de polietileno (PE) transparente de $50 \mathrm{~mm}$ de espessura. As bordas do plástico foram enterradas a $20 \mathrm{~cm}$ de profundidade tomando-se o cuidado de evitar o acúmulo de ar sob o plástico.

O experimento foi montado com delineamento em blocos casualizados, em esquema de faixas, com oito blocos (6x24 m) contendo parcelas solarizadas e não solarizadas $(3 \times 24 \mathrm{~m})$. Cada parcela constou de quatro subparcelas $(3 \times 6$ $\mathrm{m})$ com os seguintes tratamentos: testemunha (sem adição de resíduos), adição de resíduos de brássicas (mistura da parte aérea de couve-flor e brócolis 1:1 ( $2 \% \mathrm{v}: \mathrm{v})$, adição de cama de frango ( $2 \%$ $\mathrm{v}: \mathrm{v})$ e tratamento com brometo de metila $\left(40 \mathrm{~cm}^{3} / \mathrm{m}^{2}\right)$. A cama de frango foi composta por palha de arroz e esterco de aves matrizes. Os resíduos cama de frango e de brássicas foram incorporados com enxada rotativa. Nas parcelas tratadas com brometo de metila, a fumigação foi feita após o processo de solarização. $\mathrm{O}$ solo foi solarizado por 65 dias, de 28/ 08 a 03/11/03 e, após a retirada do plástico, a área foi plantada com tomate cv. TSW-10, de crescimento semi-determinado. As mudas foram transplantadas 21 dias após a semeadura em bandejas de isopor contendo substrato. As plantas foram conduzidas em estacas com espaçamento de 1,0 m entre linhas e 40 $\mathrm{cm}$ entre plantas, com densidade de plantio de 25.000 plantas por ha e 45 plantas por subparcela. Durante todo o desenvolvimento das plantas foi deter- minada a incidência de murcha bacteriana em oito plantas marcadas em cada subparcela, semanalmente, totalizando oito avaliações. Os dados de incidência da doença foram utilizados para calcular as curvas de progresso da doença e a área abaixo da curva de progresso da doença (AACPD) em cada tratamento. Após a solarização foram coletadas amostras de solo na profundidade de 0 $10 \mathrm{~cm}$ e analisadas quimicamente quanto a $\mathrm{pH}, \mathrm{P}, \mathrm{K}, \mathrm{Ca}, \mathrm{Mg}, \mathrm{S}, \mathrm{Al}, \mathrm{H}+\mathrm{Al}$, matéria orgânica, $\mathrm{Cu}, \mathrm{Fe}, \mathrm{Zn}, \mathrm{Mn}$ e B. Para determinação do banco de sementes de plantas invasoras foram coletadas amostras compostas de solo no perfil de $0-20 \mathrm{~cm}$ de profundidade, num total de $8 \mathrm{~L}$ de terra peneirada e seca ao ar por subparcela. As amostras foram utilizadas para avaliação do banco de sementes através da técnica de germinação em casa de vegetação, conforme descrito por Gross (1990) e Schreiber et al. (1989). Foi determinado também o número de plantas invasoras emergidas nas parcelas, 44 dias após o transplante do tomate, em amostras de $2000 \mathrm{~cm}^{2}$ da área útil de cada subparcela. As variáveis climáticas foram monitoradas diariamente pela estação agroclimatológica da Embrapa Hortaliças.

\section{RESULTADOS E DISCUSSÃO}

Durante o período de solarização do solo, as temperaturas médias do ar, no mês de setembro e outubro, foram respectivamente: temperaturas máximas (15 horas) $29,7^{\circ} \mathrm{C}$ e $30,3^{\circ} \mathrm{C}$; temperaturas mínimas ( 9 horas) $15,3^{\circ} \mathrm{C}$ e $18,0^{\circ} \mathrm{C}$; e insolação 9,1 e 7,5 horas. Neste experimento, foram registradas temperaturas médias do solo nas parcelas solarizadas a $5 ; 10$ e $20 \mathrm{~cm}$ de profundidade igual a $45^{\circ} \mathrm{C} ; 40,5^{\circ} \mathrm{C}$ e $34,6^{\circ} \mathrm{C}$, respectivamente, entre 14:00 e 15:00 horas. Nas parcelas não solarizadas as temperaturas médias obtidas foram $34,6^{\circ} \mathrm{C} ; 30,4^{\circ} \mathrm{C}$ e $27,2^{\circ} \mathrm{C}$ a $5 ; 10$ e $20 \mathrm{~cm}$ de profundidade, respectivamente. Estes valores correspondem a uma diferença de temperatura entre o solo solarizado e não solarizado de $10,4^{\circ} \mathrm{C}$ a $5 \mathrm{~cm}$ de profundidade, $10,1^{\circ} \mathrm{C}$ a $10 \mathrm{~cm}$ de profundidade e $7,4^{\circ} \mathrm{C}$ a $20 \mathrm{~cm}$ de profundidade.

A temperatura é um dos fatores que mais afetam a sobrevivência e o cresci- mento dos microrganismos. Em doze estudos sobre efeito da temperatura no crescimento de $R$. solanacearum, a temperatura ótima de crescimento variou de 27 a $37^{\circ} \mathrm{C}$; a temperatura máxima variou de 35 a $41^{\circ} \mathrm{C}$ e a temperatura letal variou de 45 a $55^{\circ} \mathrm{C}$ (Kelman, 1953). De acordo com a revisão de Kelman, as temperaturas alcançadas nos solos solarizados, são consideradas letais à bactéria somente a $5 \mathrm{~cm}$ de profundidade. No entanto, deve-se considerar que no solo a sobrevivência da bactéria envolve dificuldades maiores que no meio de cultura, inclusive devido à atividade de microrganismos competidores do solo e dinâmica de nutrientes, o que explica os resultados obtidos.

Houve aumento da quantidade de doença em função do tempo nos tratamentos testemunha, cama de frango $2 \%$ e resíduos de brássica $2 \%$, não solarizados. Os tratamentos solarizados não exibiram incrementos significativos da doença em função do tempo nos tratamentos testemunha e cama de frango (Figura 1). As parcelas solarizadas e não solarizadas onde foi utilizado brometo de metila apresentaram desenvolvimento semelhante da doença, comparável aos tratamentos solarizados, verificando-se que o uso do brometo de metila, mesmo em solo não solarizado reduz o progresso da doença (Figura 1C). No entanto diversas restrições ao uso do brometo de metila, incluíndo a sua elevada toxidez e seus efeitos sobre a camada de ozônio levaram a proibição do seu uso. O comportamento da doença no solo solarizado é indicativo da possibilidade do uso da solarização como alternativa ao uso do brometo de metila no controle da murcha bacteriana. A quantidade total de doença no campo obtida pelo cálculo da área abaixo da curva de progresso da doença (AACPD) indica o efeito significativo dos tratamentos sobre a incidência da murcha bacteriana. $\mathrm{O}$ uso do brometo de metila e da cama de frango (2\%) tiveram efeitos significativos na redução da incidência da murcha bacteriana no campo (Figura 2). Os tratamentos testemunha e adição de resíduo de brássicas $2 \%$ apresentaram quantidade de doença significativamente maior. Nos solos solarizados, embora a tendência do efei- 

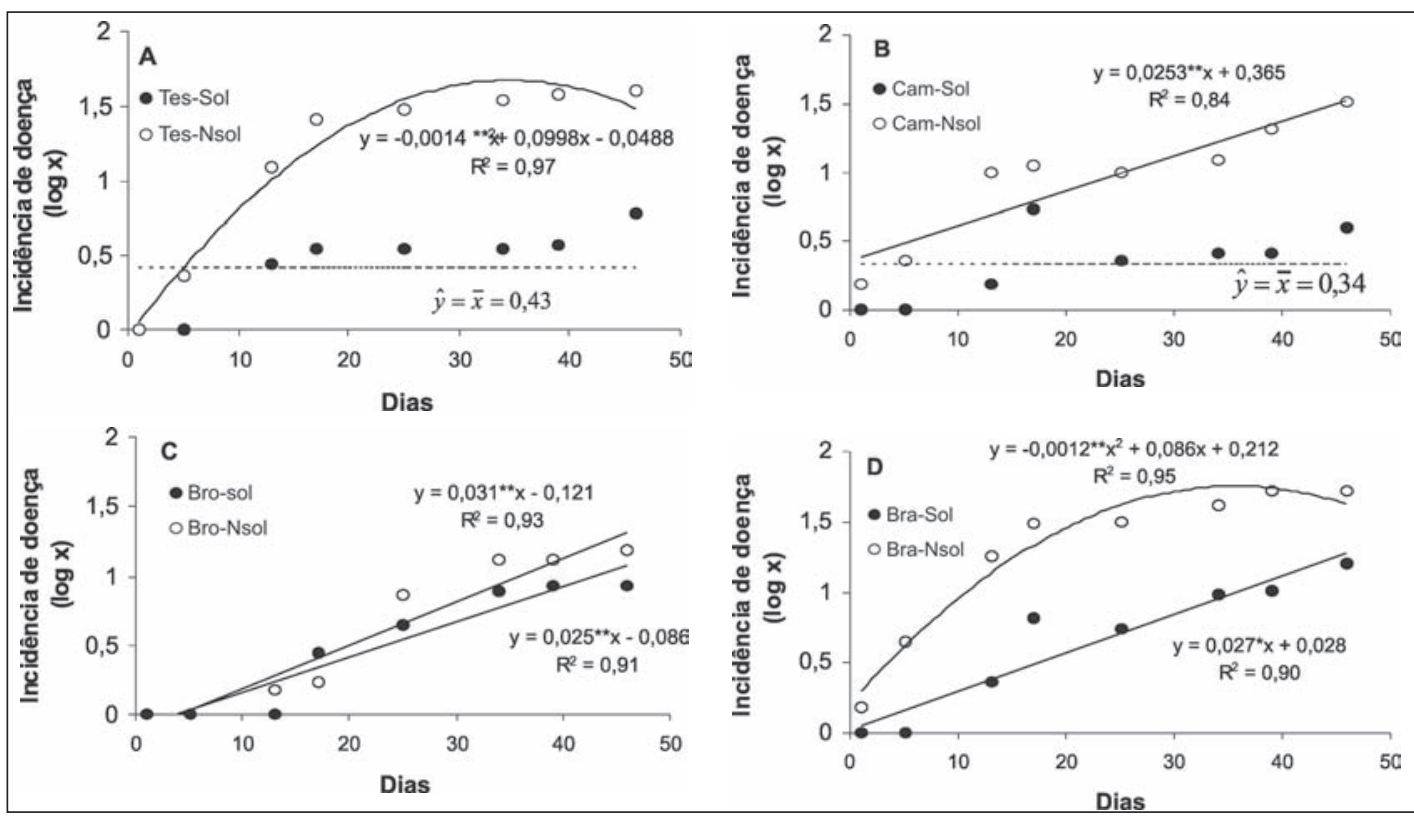

Figura 1. Curvas de progresso da murcha bacteriana em tomate nos tratamentos solarizado (•) e não solarizado (o), testemunha (A), cama de frango $2 \%$ (B), brometo de metila (C) e resíduos de brássicas $2 \%$ (D). Os valores de incidência de doenças foram transformados por Log (x) e correspondem à: $100 \%$ de doença $(2), 32 \%(1,5), 10 \%(1)$ e $3,2 \%(0,5)(* *$ significativo a $1 \%)$.

to dos tratamentos das subparcelas tenha sido semelhante aos solos não solarizados, não houve diferença significativa entre o uso do brometo de metila, testemunha, adição de cama de frango e resíduos de brássicas. A solarização aparentemente reduziu as diferenças nos tratamentos. Os resíduos de brássicas vêm sendo descritos como substâncias com ação antimicrobiana devido à presença de glucosinolatos em seus tecidos, que após sofrerem hidrólise, liberam compostos de enxofre que são tóxicos a diversos microrganismos do solo (Gamliel \& Stapleton, 1993b). Neste trabalho não se verificou o efeito destes resíduos na incidência de murcha bacteriana no campo. A adição de cama de frango, por outro lado, mostrou-se efetiva na redução da incidência da murcha bacteriana, o que foi observado também por Coca (2001). O efeito da cama de frango foi observado isoladamente e em conjunto com a solarização. Neste último caso, embora não tenha diferido significativamente do efeito da solarização sem adição do resíduo, verifica-se uma tendência de efeito aditivo que deve ser melhor estudado

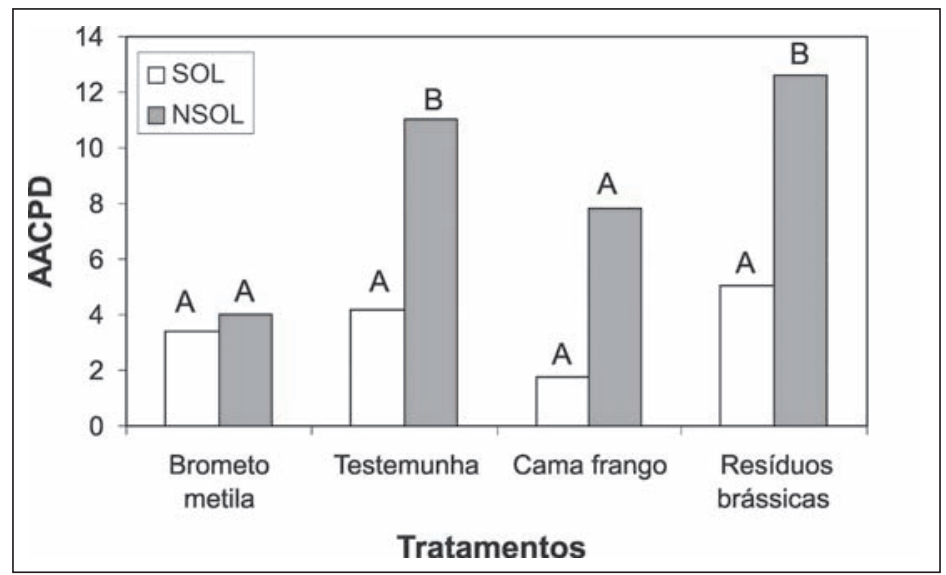

Figura 2. Área abaixo da curva de progresso da doença (AACPD), da murcha bacteriana em tomate. SOL (solarizado), NSOL (não solarizado). Barras com a mesma letra não diferem significativamente pelo teste de Scott-Knott $5 \%$.

em trabalhos posteriores. O uso da cama de frango no controle de doenças do solo vem sendo estudado devido aos efeitos da adição de resíduos ricos em nitrogênio na sobrevivência de patógenos do solo (Gamliel \& Stapleton, 1993a, 1993b). A liberação de compostos voláteis de nitrogênio $\left(\mathrm{NO}_{2}, \mathrm{NH} 3{ }^{-}\right)$durante a decomposição destes resíduos tem ação inibidora sobre diversos patógenos (Gamliel \& Stapleton, 1993a, 1993b).

Neste trabalho, embora tenha havido forte tendência de redução na incidência da murcha bacteriana (AACPD) nos tratamentos solarizados (Figura 2), os resultados não foram estatisticamen- 
Tabela 1. Características químicas da camada 0 a $10 \mathrm{~cm}$ de profundidade do solo submetido à solarização e à adição de fontes de matéria orgânica. Brasília, 2003

\begin{tabular}{|c|c|c|c|c|c|c|c|c|c|c|c|c|c|c|c|c|c|}
\hline \multirow{2}{*}{ Tratamento } & \multirow{2}{*}{ Sol. } & \multirow{2}{*}{$\begin{array}{l}\text { M.O. } \\
\text { mg kg }^{-1}\end{array}$} & \multirow{2}{*}{$\mathrm{PH}$} & $\mathbf{P}$ & $\mathbf{K}$ & $\mathrm{Na}$ & $\mathbf{s}$ & $\mathrm{H}+\mathbf{A l}$ & $\mathrm{Ca}$ & $\mathrm{Mg}$ & СтC & \multirow{2}{*}{ V (\%) } & $\mathrm{Cu}$ & $\mathrm{Fe}$ & $\mathrm{Zn}$ & Mn & B \\
\hline & & & & & $\mathrm{mg}$ & $\mathrm{dm}^{-3}$ & & & cmolc & $\mathrm{dm}^{-3}$ & & & \multicolumn{5}{|c|}{$\mathrm{mg} \mathrm{dm}^{3}$} \\
\hline \multirow{2}{*}{ Testemunha } & Sol ${ }^{1 /}$ & 34,99 & $4,74 b^{2 l}$ & 12,50 & 233,88 & 82,38 & 60,81 & 7,68 & 2,71 & 0,92 & 12,26 & 37,34 & 1,23 & 83,01 & 1,69 & 68,23 & 0,11 \\
\hline & Nsol & 36,59 & $4,91 \mathrm{a}$ & 11,05 & 253,75 & 88,00 & 53,06 & 7,43 & 2,79 & 0,90 & 12,15 & 38,87 & 1,33 & 88,76 & 1,71 & 77,86 & 0,14 \\
\hline \multirow{2}{*}{$\begin{array}{l}\text { Cama de } \\
\text { frango }\end{array}$} & Sol & 35,66 & $4,91 \mathrm{~b}$ & 36,41 & 331,25 & 112,25 & 58,61 & 7,34 & 3,78 & 1,07 & 13,52 & 45,72 & 1,87 & 73,28 & 3,71 & 99,27 & $0,13 b$ \\
\hline & Nsol & 37,64 & $5,06 \mathrm{a}$ & 32,44 & 353,75 & 116,38 & 54,93 & 7,10 & 3,79 & 1,04 & 13,35 & 46,75 & 1,74 & 80,04 & 4,06 & 85,34 & $0,21 \mathrm{a}$ \\
\hline \multirow{2}{*}{$\begin{array}{l}\text { Res. } \\
\text { Brássicas }\end{array}$} & Sol & 36,59 & $4,86 \mathrm{~b}$ & 15,41 & 306,25 & 95,00 & 59,23 & 7,39 & 3,11 & 0,74 & 12,43 & 40,54 & 1,17 & 84,56 & $1,78 \mathrm{~b}$ & 82,18 & $0,11 \mathrm{~b}$ \\
\hline & Nsol & 37,29 & $5,01 \mathrm{a}$ & 15,09 & 316,25 & 101,25 & 55,31 & 7,29 & 3,13 & 0,94 & 12,62 & 42,19 & 1,26 & 92,90 & $2,58 a$ & 76,74 & $0,20 a$ \\
\hline
\end{tabular}

Médias seguidas pela mesma letra ${ }^{2 /}$ não são significativamente diferentes pelo teste Tukey a $5 \%$ de probabilidade; ${ }^{1}$ Sol= solarizado; Nsol= não solarizado.

te significativos, possivelmente devido aos altos níveis de variação de dados em experimentos com doenças do solo no campo. No entanto, foram verificadas diferenças no progresso da doença em solos solarizados e não solarizados (Figura 1). São necessários estudos mais específicos para obter resultados mais claros sobre o efeito da solarização na incidência da murcha bacteriana.

Os efeitos da solarização do solo no controle de murcha bacteriana, além da ação direta do calor e dos efeitos na microbiota do solo podem ocorrer também pela ausência de crescimento de plantas invasoras sob o plástico durante os 65 dias da solarização do solo. O efeito do controle de plantas daninhas na incidência da murcha bacteriana foi observado por Devi et al. (1981). Estes autores verificaram que $R$. solanacearum sobreviveu na rizosfera de plantas não hospedeiras das famílias Acanthaceae e Leguminosae, mesmo na ausência das plantas hospedeiras. A severidade da murcha bacteriana foi significativamente reduzida em parcelas onde as plantas invasoras foram eliminadas com o uso de herbicidas. Portanto, a redução na população de $R$. solanacearum pode ocorrer não só pelo efeito da solarização diretamente através do calor e de seus efeitos bióticos e abióticos no solo mas também pelo fato de que o plástico mantém o solo livre de plantas invasoras durante todo o período de solarização, impossibilitando a multiplicação e dificultando a sobrevivência da bactéria. A solarização do solo influenciou significativamente o número de sementes viáveis no solo, considerando-se o total de plantas invasoras e de monocotiledôneas (Tabela 2). A solarização do solo atua nas sementes ou propágulos das plantas através da ação direta do calor e da umidade, quei- ma de plântulas germinadas e alterações no balanço de gases $\mathrm{O}_{2} / \mathrm{CO}_{2}$, acetaldeído, etileno, dentre outros, que afetam a dormência e germinação das sementes e a sobrevivência das plantas (Elmore, 1991). Diversos autores têm demonstrado o efeito da solarização sobre emergência de plantas invasoras (Ghini et al., 1993; Ambrósio et al., 2000; Sinigaglia et al., 2001). Nos tratamentos onde se utilizou cama de frango não houve efeito significativo sobre o banco de sementes, mas o número de plantas emergidas após o transplantio foi maior, indicando o favorecimento do desenvolvimento de plantas invasoras, possivelmente devido a maior fertilidade do solo, aumento nos teores de $\mathrm{P}, \mathrm{Ca}, \mathrm{Cu}, \mathrm{Zn}$, redução dos teores de $\mathrm{Al}$ e maiores CTC e saturação por bases (Tabela 1). Segundo Barberi (2002), a dinâmica das comunidades de plantas invasoras pode ser muito influenciada pelas estratégias de fertilização. A liberação rápida de nutrientes geralmente é vantajosa para plantas invasoras, que são hábeis em absorver mais rápida e eficientemente os nutrientes nos primeiros estágios de crescimento (Jornsgard et al., 1996; Liebman \& Davis, 2000). O uso da solarização para o controle de plantas invasoras apresentou boas perspectivas e deve ser investigado com maior atenção. Embora não seja tão eficiente quanto o controle químico, conforme verificado nas parcelas tratadas com brometo de metila (Tabela 2), não apresenta os problemas de toxidade e danos ao meio ambiente, configurando-se em um alternativa bastante interessante principalmente quando se considera as demandas dos sistemas orgânicos de produção.

Quanto aos efeitos dos tratamentos na fertilidade do solo, a solarização do solo causou redução do $\mathrm{pH}$ em todos os tratamentos (Tabela 1). Nos solos que receberam cama de frango e resíduos de brássicas, a solarização causou redução nos teores de boro e, nos tratamentos que receberam resíduos de brássicas, ocorreu redução no teor de zinco. Grünzweig et al. (1999) observaram redução no $\mathrm{pH}$ e no teor de zinco do solo após solarização de 7,05 para 6,47 e 3,53 para $1,95 \mathrm{mg} \mathrm{kg}^{-1}$, respectivamente. As temperaturas elevadas durante a solarização podem favorecer o aumento da população microbiana saprofítica (Ghini et al., 2002) que, ao decompor os resíduos vegetais no processo de mineralização e formação de substâncias húmicas, produzem prótons $\left(\mathrm{H}^{+}\right)$e ácidos orgânicos solúveis, contribuindo para acidificar o meio. Além disso, a matéria orgânica apresenta radicais carboxílicos e fenólicos que se dissociam liberando prótons $\left(\mathrm{H}^{+}\right)$na solução do solo.

$\mathrm{O}$ teor de matéria orgânica não diferiu entre os tratamentos (Tabela 1), resultado também observado por Ghini et al. (2003). Embora tenha havido liberação de nutrientes, provavelmente as quantidades liberadas são muito pequenas em relação ao estoque de nutrientes da matéria orgânica, não se refletindo rapidamente no teor de matéria orgânica do solo no intervalo de tempo do experimento. A adição da matéria orgânica ao solo resulta em aumento nos teores de nutrientes disponíveis com consequiente elevação da CTC e saturação por bases e a redução dos teores de alumínio (Tabela 1).

Existe a possibilidade da utilização da adição de cama de frango e da solarização como alternativa para o controle da murcha bacteriana em condições de campo. No entanto, devido às características de sobrevivência do patógeno no solo, deve-se salientar que qualquer tratamento dificilmente eliminará a bactéria. $\mathrm{O}$ que se obtém é a 
Tabela 2. Influência da solarização, fumigação com brometo de metila e adição de compostos orgânicos sobre o banco de sementes e ocorrência de plantas invasoras após o transplante no cultivo do tomate. Brasília-DF, 2003.

\begin{tabular}{|c|c|c|c|c|c|c|c|c|c|}
\hline \multirow{3}{*}{ Tratamento } & \multicolumn{9}{|c|}{ Banco de sementes ${ }^{2}$ ( $N^{\circ}$ de plantas emergidas) } \\
\hline & \multicolumn{3}{|c|}{ Plantas invas oras (total) } & \multicolumn{3}{|c|}{ Dic otile dôneas } & \multicolumn{3}{|c|}{ Monocotiledôneas } \\
\hline & Sol 1 & Nsol & Média & Sol & Nsol & Média & Sol & Nsol & Média \\
\hline Brometo metila & 69,6 & 92,7 & $81,2 \mathrm{~B}$ & 27,7 & 37,2 & $32,5 \mathrm{~B}$ & 41,5 & 54,6 & $47,9 \mathrm{~B}$ \\
\hline Cama frango & 189,7 & 268,1 & $228,9 \mathrm{~A}$ & 56,1 & 110,0 & $83,3 \mathrm{~A}$ & 132,2 & 157,0 & $144,6 \mathrm{~A}$ \\
\hline Res. brássicas & 197,4 & 223,5 & $210,4 \mathrm{~A}$ & 67,9 & 75,6 & $71,7 \mathrm{~A}$ & 128,1 & 146,7 & $137,4 \mathrm{~A}$ \\
\hline Testemunha & 207,7 & 238,0 & $222,9 \mathrm{~A}$ & 72,0 & 81,6 & $76,8 \mathrm{~A}$ & 134,1 & 155,6 & $144,9 \mathrm{~A}$ \\
\hline \multirow[t]{4}{*}{ Média } & $166,1 \mathrm{~b}$ & $205,6 \mathrm{a}$ & & $56,0 \mathrm{a}$ & $76,1 \mathrm{a}$ & & $108,9 \mathrm{~b}$ & $128,5 \mathrm{a}$ & \\
\hline & \multicolumn{9}{|c|}{ Número de plantas $/ \mathrm{m}^{2}$ (média de 8 repetições) } \\
\hline & \multicolumn{3}{|c|}{ Plantas invas oras (total) } & \multicolumn{3}{|c|}{ Dicotile dôneas } & \multicolumn{3}{|c|}{ Monoc otiledôneas } \\
\hline & Sol & Nsol & Média & Sol & Nsol & Média & Sol & Nsol & Média \\
\hline Brometo metila & 45,6 & 67,5 & $56,6 \mathrm{C}$ & 13,1 & 18,7 & $15,9 \mathrm{D}$ & 32,5 & 48,1 & $40,3 \mathrm{~B}$ \\
\hline Cama frango & 305,6 & 284,3 & $295,0 \mathrm{~A}$ & 130,0 & 115,6 & $137,8 \mathrm{~A}$ & 145,6 & 168,7 & $157,2 \mathrm{~A}$ \\
\hline Res. brássicas & 213,1 & 236,8 & $225,0 \mathrm{~B}$ & 65 & 59,3 & $62,2 \mathrm{C}$ & 148,1 & 177,5 & $162,8 \mathrm{~A}$ \\
\hline Testemunha & 239,3 & 225,0 & $232,2 \mathrm{~B}$ & 84,3 & 66,2 & $75,3 \mathrm{~B}$ & 155,0 & 158,1 & $156,6 \mathrm{~A}$ \\
\hline Média & 200,9 a & 203,4 a & & 80,6 a & $65,0 \mathrm{a}$ & & $120,3 \mathrm{a}$ & $138,1 \mathrm{a}$ & \\
\hline
\end{tabular}

${ }^{1} \mathrm{Sol}=$ Solo solarizado, Nso= Solo não solarizado; ${ }^{2}$ Plantas oriundas de dois fluxos de germinação de sementes presentes em amostras de solo de 8 litros (média de 8 repetições); As médias dos tratamentos seguidas de letras iguais, em letra maiúscula nas mesmas colunas e minúsculas, para cada variável, nas linhas, não diferem significativamente pelo teste de Tukey, ao nível de 5\% de probabilidade.

redução de sua população possibilitando menores perdas. Aunião de diversas medidas de controle em sistemas de manejo integrado, como o uso da solarização, cultivares com níveis significativos de resistência, práticas culturais, etc., possivelmente permitirão o controle eficiente da doença. Estudos mais detalhados sobre as melhores combinações entre os tratamentos, com diferentes porcentagens de resíduos, tempo de solarização, cultivares e avaliações econômicas da viabilidade do processo para diferentes hortaliças e sistemas de produção devem ser realizados para permitir a utilização destas técnicas efetivamente na produção de hortaliças.

\section{REFERÊNCIAS}

AMBRÓSIO MMQ; NASCIMENTO SRC; NEGREIROS MZ; OLIVEIRA OF. 2000. Controle de damping-off e plantas invasoras em tomateiro através da solarização. Fitopatologia Brasileira 25: 353 .

BARBERI P. 2002. Weed management in organic agriculture: are we addressing the right issues. Weed Research 42: 177-193.

BLOK WJ; LAMERS JG; TERMORSHUIZEM AJ; BOLLEN GJ. 2000. Control of soilborne plant pathogens by incorporating fresh organic amendments followed by tarping. Phytopathology 90: 253-259.

COCA DM. 2001. Efeito da adubação orgânica em batata (Solanum tuberosum L.) cultivada em solo infestado com Ralstonia solanacearum Biovar 1. Brasília: UNB. 57p. (Tese mestrado).

DEVI LR; MENON MR; AIYER RS. 1981.
Survival of Pseudomonas solanacearum in soil. Plant and Soil 62: 169-182.

ELMORE CL. 1991. Weed control by solarization. In: KATAN J; DEVAY J E (eds). Soil Solarization. Boca Raton: CRC Press. p. 61-72.

GAMLIELA; STAPLETON JJ. 1993 a. Effect of chicken compost or ammonium phosphate and solarization on pathogen control, rhizosphere microrganisms, and lettuce growth. Plant Disease 77: 886-891.

GAMLIEL A; STAPLETON JJ. 1993 b. Characterization of antifungal volatile compounds evolved from solarized soil amended with cabbage residues. Phytopathology 83: 899-905.

GHINI R. 2001. Alternativas para substituir o brometo de metila na agricultura. Summa Phytopathologica 27: 162.

GHINI R; PATRICIO FRA; SOUZA MD; SINIGAGLIA C; BARROS BC; LOPES MEBM; TESSARIOLI NETO J; CANTARELA H. 2003. Efeito da solarização sobre propriedades físicas, quimicas e biológicas de solos. Revista Brasileira de Ciência do solo 27: 71-79.

GHINI R; SHOENMAKER IAS; BETTIOL W. 2002. Solarização do solo e incorporação de fontes de matéria orgânica no controle de Pythium spp. Pesquisa Agropecuária Brasileira 37: 1253-1261.

GHINI R; BETTIOL W; SPADOTTO CA; MORAES GJ; PARAIBA LC; MINEIRO JLC. 1993. Soil solarization for the control of tomato and eggplant Verticillium wilt and its effect on weed and micro-arthropod communities. Summa Phytopathologica 19: 183-189.

GROSS KL. 1990. A comparison of methods for estimating seed numbers in the soil. Jounal of Ecology 78: 1079-1093.

GRÜNZWEIG JM; KATAN J; BEM-TAL Y; RABINOWITCH HD. 1999. The role of mineral nutrients in the increased growth response of tomato plants in solarized soil. Plant and Soil 206: 21-27.
HAYWARD AC. 1994. The hosts of Pseudomonas solanacearum. In: HAYWARD AC; HARTMAN GL (eds). Bacterial Wilt: the disease and its causal agent, Pseudomonas solanacearum. Wallingford: $\mathrm{CAB}$ International. p. 9-24.

JORNSGARD B; RAMUSSEN K; HIEL J; CHRISTIANSEN L. 1996. Influence of nitrogen on competition between cereals and their natural weed populations. Weed Research 36: 461-470.

KATAN J. 1981. Solar heating (solarization) of soil for control of soilborne pests. Annual Review of Phytopathology 19: 211-36.

KELMAN A. 1953. The bacterial wilt caused by Pseudomonas solanacearum: a literature review and bibliography. Technical Bulletin 99 , North Carolina Agricultural Experiment Station.

LIEBMAN M; DAVIS AS. 2000. Integration of soil crop and weed management in low external input farming systems. Weed Research 40: $27-47$.

LOPES CA; SANTOS JR; ÁVILA AC; BEZERRA IC; CHARCHAR JM; QUEZADODUVAL AM. 2000. Doenças: identificação e controle. In: SILVA JBC; GIORDANO LB, (eds). Tomate para processamento industrial. Brasília: Embrapa Comunicação para Transferência de Tecnologia: Embrapa Hortaliças. p. 88-111.

SCHREIBER RL; LECK MA; PARKER VT. 1989. Seed banks: general concepts and methodological issues. In: LECK MA; PARKER VT; SIMPSON RL (eds). Ecology of soil seed banks. London: Academic Press. p. 3-8.

SINIGAGLIA C; PATRICIO FRA; GHINI R; MALAVOLTA VMA; TESSARIOLI J; FREITAS SS. 2001. Controle de Sclerotinia minor, Rhizoctonia solani e plantas invasoras em alface pela solarização do solo e sua integração com controle químico. Summa Phytopathologica 27: 229-235. 